\title{
Tobacco Use Basic Biological Research
}

National Cancer Institute

\section{Source}

National Cancer Institute. Tobacco Use Basic Biological Research. NCI Thesaurus. Code C15988.

Laboratory-based research studies that assess the effects of tobacco and tobacco products on cell biology and cellular mechanisms of action, including the role of tobacco and tobacco byproducts in the initiation and promotion of cancer and the biological. $(\mathrm{NCl} / \mathrm{TRIP})$ 